\title{
SPATIAL DUOPOLY UNDER UNIFORM DELIVERED PRICING WHEN FiRMS A VOID TURNING CUSTOMERS AWAY
}

di

Alberto Iozzi

\section{Introduction}

Uniform delivered pricing (UDP henceforth) policies are widely adopted in many industries. Firms are said to set a uniform delivered price when they charge the same price to all the customers irrespective to their location and bear the cost of delivering the good. Greenhut (1981) points out that about a quarter of firms in a sample of more than 200 in USA, West Germany and Japan set uniform delivered prices. Similarly, Phlips (1983) provides some evidence of UDP policies being used in the cement and brick industries, and of its relevance in industries where transport constitutes a substantial part of firms' costs. This evidence carries over to the present time where simple casual observation allows to see UDP policies adopted by many firms like, for instance, mailing firms and furniture and domestic appliances retailers.

In spite of this, the analysis of spatial oligopoly under uniform delivered pricing has been a relatively neglected topic in the economic literature. The main reason for this is that UDP models suffer from problems of existence of the equilibrium in pure strategies even more seriously than other spatial models (Schuler and Hobbs, 1982, and Beckmann and Thisse, 1986). Several strategies have been used in the literature to overcome this problem. One of the most widely used is to assume that products sold by different firms are heterogeneous, although different approaches to product heterogeneity have been taken in the literature. Some authors assume that consumers' demand is given 
by a logit function, with consumers buying some fraction of the goods from either firms (see e.g. De Palma et al., 1987, and Anderson et. al., 1992b). Other scholars assume that consumers view the goods supplied by the different firms as imperfect substitutes and demand varies continuously as prices vary (De Fraja and Norman, 1993).

The main focus of this paper is on the issue of the existence of equilibrium in a UDP duopoly model and on its characterisation when products are homogeneous. The paper shows that an equilibrium exists even with perfect product homogeneity. This result is shown in a model which is very similar to the ones typical in this literature, but that differs from them in one important respect. It is assumed that, as firms cannot choose the dimension of the market they supply, no rationing can occur. More precisely, if a firms sells the good in one market at a given price, it has to supply also all the other markets at the same price, unless these are served by the rival at the same or lower price. The main rationale for this assumption is that firms may face a cost to turning down customers. This means that if a firm refuses to supply consumers in one market at the same price applied in some other market, it faces a positive cost. Turning down customers may be costly in term of goodwill, reputation or offence caused. The presence of this costs has already been assumed in the literature (see Dixon, 1990) and it is standard in Operational Research and inventory models (see, e.g. Taha, 1988 for textbook treatment and references). While the existence of a cost to turning customers away is not explicitly modelled here, it is clear that a sufficiently high cost of turning customers away makes it preferable for the firm to serve even markets where revenues are smaller than the production and delivery costs.

Another possible motivation of the 'no rationing' assumption is the existence of regulatory constraints. For instance, regulatory 
constraints of this sort are imposed in the domestic electricity markets in the United Kingdom that has been opened to competition since 1998. In each regional market, all electricity suppliers are required by the regulator to publish their (uniform) prices and are not allowed to refuse to supply any customer in the region.

The 'no rationing' assumption is crucial in restoring the possibility of equilibrium for the following reason. In a spatial duopoly under UDP when firms can ration the supply of the good and the transportation cost is high enough, a firm may find optimal not to supply all the customers along the market line. Then, it may be optimal for the rival not to compete in price in the markets already served by the former firm but simply supply the good at the monopoly price to all the remaining markets. Clearly, this cannot be an equilibrium as the former firm would have an incentive to raise its price. The 'no rationing' assumption, by taking away from the firm the choice of the market area to serve, obliges the firm to supply all the customers when charging a price lower than the rival and prevents each firm from leaving some markets to the rival, where the latter can charge its monopoly price.

In this paper, I study a single-stage game where firms simultaneously choose prices. Firms are symmetrically located along the market line and locations are exogenous. This is the setup that has traditionally been used by the existing literature on homogeneous duopoly under UDP prices. The use of a model similar to the ones previously used highlights the role played by the 'no rationing' assumption in restoring the possibility of equilibrium.

An issue of large relevance in spatial oligopoly models is the socalled tie-breaking rule. This is the rule that solves the conflict over markets where the firms set equal prices. Following Gronberg and Meyer (1981), I study two different tie-breaking rules and characterise the equilibrium under these rules. The first 
tie-breaking rule is such that, when both firms charge the same price at the same location, the market is totally supplied by the closest firm, that is by the firm that enjoys a comparative advantage in terms of transportation costs over the rival. Under this tie-breaking rule, consumers are usually said to do the socially optimal thing and buy from the closest firm. As this rule guarantees that, for given quantities, total transportation cost is minimised, I call it efficient tie-breaking rule. The second tiebreaking rule is that, in case of matching prices, total demand in each local market is equally shared between the two firms. These equal shares may come from customers randomly selecting the firm they patronise. Then, at least in expected terms, each firm faces half of the demand in each market. In the rest of the paper, I refer to it as random tie-breaking rule.

The main results of this paper are as follows. I show that, when the transportation cost is not too high to hamper the profitability of the firms, there exists at least one equilibrium of the game. Not surprisingly, it is found that the nature of the equilibria of the model are deeply different according the tie-breaking rule adopted.

Typically, there exists multiple equilibrium price pairs under the efficient tie-breaking rule. Any symmetric price pair within a given range is a Nash equilibrium, with each firm serving exactly half of the market line. The upper bound of this range is the price that makes the firm indifferent between matching and undercutting the rival; any price higher than this is such that firms are better off undercutting and serving the whole market. The lower bound of the interval is the price such that any firm make zero profits when serving half of the market line; any price lower than this is such that firms make negative profits even if they match the rival and serve only half of the market line. When both firms set the same price within this interval, it is not profitable for 
a firm to undercut. This is because it would have to serve the whole market line, facing too high a transportation cost.

In the game under the random tie-breaking rule, there is only one equilibrium price, where both firms make zero profits. As firms equally share each local market when setting the same price, undercutting is profitable at all price but the one that brings about zero profits. Then, the only equilibrium price is the one that gives zero profits to each firm.

The paper also provides some indications on the welfare properties of the equilibria of the game under the different tiebreaking rules. It is interesting to note that for low values of the transportation cost, aggregate consumers' welfare is higher under the random tie-breaking rule despite its ex-post inefficiency. In other words, consumers are better off selecting randomly which firm they patronise than adopting the so-called socially optimal behaviour. On the other hand, the welfare of the society is always higher under the efficient tie-breaking rule. This is partly due to the zero profits obtained by the firms under the other tie-breaking rule.

The structure of the paper is as follows. The model is described in section 2. Sections 3 and 4 characterise the equilibria of the game under the different tie-breaking rules. Section 5 makes some normative judgements on the different market arrangements. Some concluding remarks are given in Section 6.

\section{The model}

I assume a spatial linear market in which competition in prices between two profit-maximising firms takes place at each point on the market line. Consumers are evenly distributed over the line. At each location along the line, consumers have elastic demand given 
by $q=1-p$. Consumers' density and length of the market line are both normalised to 1 .

The two firms produce perfectly homogeneous goods; the firms are referred to as firm 0 and firm 1 . The pricing policy adopted by both firms is uniform delivered pricing: the same price is charged to all customers, irrespective of their location, and firms deliver the good to customers' locations at their cost. Each firm produces with constant (and identical) marginal and average cost that, without further loss of generality, is normalised to zero. Transportation cost (denoted by $c$ ) is assumed to be linearly increasing with quantity and distance. Transport is under firms' control and no arbitrage can take place among consumers.

I assume that firms cannot ration the supply of the good in any of the markets. This implies that, once a price has been set by one of the two firms, all the customers have the right to buy at that price from that firm, unless their demand is satisfied by the rival firm at the same or lower price. From this assumption, it follows that if one of the firms sets a price lower than the rival, it may end up serving all the customers along the unit line.

If the two firms charge the same price, two different rules on the resolution of the conflict over markets are studied:

- efficient tie-breaking rule: the first tie-breaking rule is such that, in case of both firms charging the same price at the same location, the market is supplied by the closest firm, that is by the firm which bears a lower transportation cost in serving that location. In the rest of the paper, this tie-breaking rule is usually referred to as the efficient tie-breaking rule and all the variables related to it are denoted by the superscript $E$.

- random tie-breaking rule: the second tie-breaking rule is such that, in case of both firms charging the same price at the same location, total demand in each local market is equally shared 
between the two firms. This tie-breaking rule is referred to as random in the rest of the paper and all the variables related to it are denoted by the superscript $R$.

These rules are usually interpreted in the literature as originating from different behaviour on the consumers' side. As for the efficient tie-breaking rule, it is assumed that consumers buy from the nearest firm (see e.g. Lederer and Hurter, 1986, and MacLeod et al., 1988). This behaviour is usually defined as socially optimal because, given the quantities exchanged and the locations of the two firms, it minimises the total transportation cost. As for the random tie-breaking rule, this may be the result of customers selecting randomly the firm from which to buy; then, if assigning an equal probability to buying from each firm, each local market is equally shared between the firms supplying that market (at least in expected terms). Following Gronberg and Meyer (1981), another possible interpretation of the tie-breaking rules makes them dependent on firms' behaviour. The efficient tie-breaking rule can be interpreted as the result of a collusive behaviour between the two firms. Under this interpretation, firms collude over the locations they serve, provided that all demand at each location is satisfied. Collusion implies that firms agree to share markets at any location so that each firm serves exclusively the locations where it has a comparative advantage in terms of costs with respect to the rival. On the contrary, the random tiebreaking rule can be interpreted as the result of the firms being not able or not allowed to reach the collusive agreement on the locations each firm has to serve exclusively. In this case, firms split each local market.

I model the strategic interaction between the two firms as a single-stage game where locations are fixed and each firm simply chooses the level of price $v_{i} \in[0,1]$ where $i=0,1$. As most of the literature, I restrict my attention to the case where firms 
locations are symmetric ${ }^{1}$. Then, without loss of generality, I restrict the locations to be such that $x_{0} \in\left[0,1 y_{2}\right.$ and $x_{1} \in[1 / 21]$. Given the nature of the game, the equilibrium concept is Nash equilibrium.

Denoting with $x_{0}$ and $x_{1}$ the locations of firm 0 and 1 respectively, in case of the efficient tie-breaking rule, firm 0's profits are given by

$$
\Pi_{0}^{E}\left(v_{0}, v_{1}\right)= \begin{cases}0 & \text { when } v_{0}>v_{1} \\ \int_{0}^{1 / 2}\left(v_{0}-c\left|x-x_{0}\right|\right)\left(1-v_{0}\right) d x & \text { when } v_{0}=v_{1} \\ \int_{0}^{1}\left(v_{0}-c\left|x-x_{0}\right|\right)\left(1-v_{0}\right) d x & \text { when } v_{0}<v_{1}\end{cases}
$$

while, in case of the random tie-breaking rule, firm 0's profits are given by

$$
\Pi_{0}^{R}\left(v_{0}, v_{1}\right)= \begin{cases}0 & \text { when } v_{0}>v_{1} \\ \int_{0}^{1}\left(v_{0}-c\left|x-x_{0}\right|\right) 1 / 2\left(1-v_{0}\right) d x & \text { when } v_{0}=v_{1} \\ \int_{0}^{1}\left(v_{0}-c\left|x-x_{0}\right|\right)\left(1-v_{0}\right) d x & \text { when } v_{0}<v_{1}\end{cases}
$$

Similar formulae apply for firm 1.

\footnotetext{
${ }^{1}$ This assumption is not strictly necessary for my results. Iozzi (1999) shows that an equilibrium exists even with asymmetric locations under rather mild restrictions on the firms' locations.
} 


\section{The equilibrium under the efficient tie-breaking rule}

This section characterises the equilibrium of the single-stage price game under the efficient tie-breaking rule. I recall here that this implies that when the two firms set the same price, firms end up serving only those locations where they have a comparative advantage over the rival in term of transportation cost. Let $x_{0}=x$ and $x_{1}=1-x$, where $x$ gives the distance from firm 0's location (respectively, firm 1's) to the left (right) end of the market line.

Before proceeding into the characterisation of the equilibrium, I introduce the following definition.

Definition 1. Let $V_{e} \equiv\{v \in \mathfrak{R}: v \in[\underline{v}, \bar{v}]\}$, where

$$
\underline{v} \equiv c\left(\frac{1}{4}-x+2 x^{2}\right) \text { and } \bar{v} \equiv c\left(\frac{3}{4}-x\right) \text {. }
$$

$V_{e}$ is the set of all real numbers weakly greater than $\underline{v}$ and weakly smaller than $\bar{v}$. It plays a crucial role in the characterisation of the Nash equilibrium prices in the game under analysis because it includes all those price levels that, if set by one of the two firms, the rival firm finds optimal to match.

The lower boundary of $V_{e}$ is obtained setting to zero the profit of either firm when both firms charge the same price and solving with respect to the price. As profits for each firm are decreasing in price in case of matching prices, $\underline{v}$ gives the lowest price consistent with non-negative profits when each firm matches the price set by the rival and supplies only the customers in its half of the market line. Formally, $\underline{v}$ is the smallest solution to $\left.\Pi_{i}^{E}\left(v_{i}, v_{j}\right)\right|_{v_{i}=v_{j}}=0$, for $i=0,1$ and $i \neq j$. 
The upper boundary of $V_{e}$ is obtained equalising the profits obtained by either firm when it undercuts with the profits obtained when it matches the price set by the rival and solving for the price. Note also that for any price below $\bar{v}$ the profits for each firm are higher when matching the rival than when undercutting, while the opposite holds for any price above $\bar{v}$. Then, $\bar{v}$ gives the highest price for which each firm prefers to match the rival rather that undercutting. Formally, $\bar{v}$ is the smallest solution to $\left.\Pi_{i}^{E}\left(v_{i}, v_{j}\right)\right|_{v_{i}=v_{j}}=\left.\Pi_{i}^{E}\left(v_{i}, v_{j}\right)\right|_{v_{i}<v_{j}}$, for $i=0,1$ and $i \neq j$.

A useful property of $V_{e}$ is stated in the following lemma.

Lemma 1. $V_{e}$ is not empty.

Proof. Simply by noting that $\bar{v}-\underline{v}>0$ when $x \in[0,1 / 2$ and that $\underline{v}=\bar{v}$ when $x=1 / 2$

This Lemma will be useful in the rest of this section to show that an equilibrium always exists in the game under analysis.

The following Proposition characterises the equilibrium of the price game in case of the efficient tie-breaking rule.

Proposition 1. Let $c<\frac{4}{1-4 x+8 x^{2}}$. Any Nash equilibrium of the game under the efficient tie-breaking rule is a pair of prices $v_{0}$ and $v_{1}$ such that $v_{0}=v_{1}$ and $v_{0}, v_{1} \in V_{e}$.

Proof: Nash equilibrium prices are obtained in the following way: 
$i$. an equilibrium must be a single price equilibrium. Let $v_{i}^{0}$ be the smallest solution to $\left.\Pi_{i}^{E}\left(v_{i}, v_{j}\right)\right|_{v_{i}<v_{j}}=0$, for $i=0,1$. By symmetry of locations and costs conditions between the two firms, note that $v_{i}^{0}=v_{j}^{0}$ for $i, j=0,1$ and $i \neq j$. By contradiction, assume that an equilibrium price pair $v_{i}$ and $v_{j}$ such that $v_{i} \neq v_{j}$ exists. Without loss of generality, let $v_{i}<v_{j}$. If $v_{i}<v_{j}<v_{i}^{0}$ or $v_{i}<v_{i}^{0}<v_{j}$, note that $0=\Pi_{i}^{E}\left(v_{j}+\varepsilon, v_{j}\right)>\Pi_{i}^{E}\left(v_{i}, v_{j}\right)$ for $\forall \quad v_{i}, \quad v_{j}$, which contradicts the initial assumption on $v_{i}$ and $v_{j}$. Also, if $v_{i}^{0}<v_{i}$ $<v_{j}, \Pi_{j}^{E}\left(v_{i}-\varepsilon, v_{i}\right)>\Pi_{i}^{E}\left(v_{j}, v_{i}\right)$, with $\varepsilon$ positive and whatever small and for $\forall v_{i}$ and $v_{j}$.

ii. any pair of prices $v_{0}$ and $v_{1}$ such that $v_{0}=v_{1}$ and $v_{0}, v_{1} \notin V_{e}$ cannot be an equilibrium. If $v_{i}=v_{j}<\underline{v}$, then $0=\Pi_{i}^{E}\left(v_{i}+\varepsilon, v_{j}\right)>\Pi_{i}^{E}\left(v_{i}, v_{j}\right)$, with $\varepsilon$ positive and whatever small; if $v_{i}=v_{j}>\bar{v}$, then $\Pi_{i}^{E}\left(v_{j}-\varepsilon, v_{j}\right)>\Pi_{i}^{E}\left(v_{i}, v_{j}\right)$ with $\varepsilon$ positive and whatever small. In both cases, firms prefers to charge a price different from the rival, contradicting step $i$.

iii. any pair of prices $v_{0}$ and $v_{1}$ such that $v_{0}=v_{1}$ and $v_{0}, v_{1} \in V_{e}$ is a Nash equilibrium. Let firm $i$ set $v_{i} \in V_{e}$. Firm $j^{\prime}$ 's optimal response is to charge $v_{j}=v_{i}$ as $\Pi_{j}^{E}\left(v_{j}, v_{i}\right)>\Pi_{j}^{E}\left(v_{j}{ }^{\prime}, v_{i}\right)$ for any $v_{j}{ }_{j} \neq v_{j}$. This is because, by the way $V_{e}$ is defined, if $v^{{ }_{j}}<$ $v_{i}$, then $\Pi_{j}^{E}\left(v_{j}{ }^{\prime}, v_{i}\right)<\Pi_{j}^{E}\left(v_{j}, v_{i}\right)$ as firm $j$ would serve all the customers along the line. On the other hand, if $v_{j}^{\prime}>v_{i}$, 
$0=\Pi_{j}^{E}\left(v_{j}{ }^{\prime}, v_{i}\right)<\Pi_{j}^{E}\left(v_{j}, v_{i}\right)$, as no consumer would buy from firm $j$.

The restriction on the value of $c$ guarantees that there exists at least one price belonging to the strategy spaces of the firms that also belong to $V_{e}$. In other words, the restriction ensures that the transportation cost is small enough so that firms make nonnegative profits when they serve only the half of the market line in which they are located.

The Proposition states that any pair of identical prices higher than $\bar{v}$ in Definition 1 cannot be an equilibrium, as each firm would obtain higher profits by undercutting the rival and serving the whole market. Similarly, it argues that an equilibrium with both firms charging a price below $\underline{v}$ cannot exists, as both firms would make negative profits. Any firm would then be better off charging a higher price so to be driven out of the market and make zero profits. Take now the case of both firms setting a price falling within $\underline{v}$ and $\bar{v}$. Proposition 1 claims this is an equilibrium. To see why, assume firm $i$ sets a price $v_{i}$ that belong to $V_{e}$. According to the Proposition, the best reply for firm $j$ is to set a price $v_{j}=v_{i}$. This is because, if firm $j$ charges a higher price, it sells zero quantity. On the contrary, if it undercuts the other firm's price, it has to supply the good to all the customers. In such a case, because of the transportation cost incurred in delivering the good to customers located in more remote areas, the firm obtains lower profits than simply matching the rival.

A clearer understanding of the result in Proposition 1 can be obtained from Figure 1. In the Figure, let $v_{0}$ be the price charged by firm 0 . If firm 1 charges $v_{1}=v_{0}$ it sells to customers located 
between $x^{\prime}$ and 1 and gets average revenues equal to $v_{1} \times\left(1-x^{\prime}\right)$. Average cost is given by the sum of the areas of the two triangles $x^{\prime} \mathrm{A} x_{1}$ and $x_{1} \mathrm{BC}$. On the contrary, if firm 1 charges $v_{1}=v_{0}-\varepsilon$ (with $\varepsilon$ whatever small and positive), average revenues are given by $\left(v_{0}-\varepsilon\right) \times 1$, with average costs given by the sum of the areas of the two triangles $x_{1} \mathrm{E} 0$ and $x_{1} \mathrm{BC}$. Overall, when $\varepsilon$ is sufficiently small, the gain from undercutting the rival is given by the area $\mathrm{ADF}$, while losses are given by $v_{0} \mathrm{EF}$. As ADF is smaller than $v_{0} \mathrm{EF}$, it is clear that, undercutting the rival, losses for firm 1 are more than offset by gains: then, the firm 1 has no incentive to undercut the rival.

Insert Fig. 1 about here

I can also state the following Proposition.

Proposition 2. Let $c<\frac{4}{1-4 x+8 x^{2}}$. Under the efficient tie-breaking rule, there always exists at least one Nash equilibrium price pair.

Proof. Simply combining Lemma 1 and Proposition 1.

Proposition 1 and 2 together say that, under the efficient tiebreaking rule, there exists at least one price pair that qualifies as a Nash equilibrium price pair. Furthermore, the propositions argue that typically there exists more than one equilibrium, with any pair of identical prices within a given interval being a Nash equilibrium. The only case in which there exists only one Nash equilibrium price pair is when both firms are located right in the middle of the market line.

For the purpose of comparing the welfare properties of the markets under the efficient tie-breaking rule with those of the 
market under the random tie-breaking rule, it is useful to single out a price pair amongst the set of equilibrium price pairs. Using a focal point argument or appealing to the possibility of coordination between firms to ensure that the outcome most favourable to them emerges in equilibrium, I concentrate on the equilibrium price pair that gives to the firms the highest profits. The rest of this section is then devoted to characterising the equilibrium that emerges when both firms charge the price that gives them the highest profits among the Nash equilibrium price pairs. For firm 0 , this price comes as the solution of the following problem

$$
\max _{v_{0}} \int_{0}^{1 / 2}\left(v_{0}-c\left|x-x_{0}\right|\right)\left(1-v_{0}\right) d x
$$

$$
\text { s.t. } v_{0} \in V_{e}
$$

while a similar problem is faced by the rival. Note that because of the symmetry of cost structures and locations, the price which solves the problem for firm 0 in [3] is the same as the price which solves the similar problem faced by the rival. This implies that the focus on the profit maximising equilibrium price pair is particularly appropriate for two reasons. First, this price is a Nash equilibrium: no firm has an incentive to deviate from it. Second, no other equilibrium price gives more profits to any of the two firms. Note also that, because of the symmetry between firms, the price that gives each firm the highest level of profits is also the price that maximises the joint profits of the two firms.

The characterisation of the single-firm and joint profit maximising Nash equilibrium price pair is given in the following Proposition.

$$
\text { Proposition 3. Let } c<\frac{4}{1-4 x_{0}+8 x_{0}^{2}} \text {. Let } v_{0}^{E} \text { and } v_{1}^{E} \text { be }
$$

the Nash equilibrium price pair that gives the highest profits to the two firms under the efficient tie-breaking rule. Then, 


$$
\begin{aligned}
& v_{i}^{E}= \begin{cases}c\left(\frac{3}{4}-x\right) & \text { when } c \in\left(0, \frac{4}{5-4 x-8 x^{2}}\right] \\
\frac{1}{2}+c\left(\frac{1}{8}-\frac{1}{2} x+x^{2}\right) & \text { when } c \in\left[\frac{4}{5-4 x-8 x^{2}}, \frac{4}{1-4 x+8 x^{2}}\right)\end{cases} \\
& \text { for } i=0,1
\end{aligned}
$$

Proof: Use standard constrained maximisation techniques.

The Proposition illustrates the price pair that delivers the highest profits to the firms among the set of equilibrium price pairs. When the value of transportation cost is high enough, the Nash equilibrium price pair that gives the highest profits is simply made out of the two prices that maximise the profits of each firm given that it serves the consumers located in its half of the market line. However, for low values of the transportation cost, the unconstrained single firm profit maximising price is not an equilibrium as it falls outside the range of equilibrium price and, if charged, will be profitably undercut by the rival which would supply the entire market. Thus, for such values of $c$ the price which delivers the highest profits among the set of equilibrium prices is the upper boundary of the range of equilibrium prices.

\section{The equilibrium under the random tie-breaking rule}

This section characterises the equilibrium of the price game under the random tie-breaking rule. Recall that this implies that when the two firms set the same price, half of the demand at each location along the market line is expected to be addressed to each firm. This may occur because, as firms are identical, customers randomise their choice and buy from either firm with the same probability. Similarly as before, I set $x_{0}=x$ and $x_{1}=1-x$, where 
again $x$ gives the distance from firm 0's location (respectively, firm 1's) to the left (right) end of the market line.

Now, I can state

Proposition 4: Assume $c<\frac{2}{1-2 x+2 x^{2}}$. Let $v_{0}^{R}$ and $v_{1}^{R}$ be the Nash equilibrium price pair under the random tiebreaking rule. Then, there always exists one and only one equilibrium price pair $v_{0}^{R}$ and $v_{1}^{R}$ such that

$$
v_{i}^{R}=c\left(\frac{1}{2}-x+x^{2}\right) \quad \text { for } i=0,1 . \quad \text { [5] }
$$

Proof: First note that $v_{i}^{R}$ comes as the solution to $\left.\Pi_{i}^{R}\left(v_{i}, v_{j}\right)\right|_{v_{i}=v_{j}}=0$. Then,

i. an equilibrium must be a single price equilibrium. (See step $i$. of the proof of Proposition 1).

ii. the pair $v_{i}^{R}$ and $v_{j}^{R}$ is a Nash equilibrium pair of prices. When firm $i$ charges $v_{i}^{R}$, firm $j^{\prime}$ 's optimal response is to charge $v_{j}^{R}=v_{i}^{R}$ as $\Pi_{j}^{R}\left(v_{j}^{R}, v_{i}^{R}\right) \geq 0 \geq \Pi_{i}^{R}\left(v_{j}, v_{i}^{R}\right)$ for any $v_{j} \neq v_{j}^{R}$. Indeed, if firm $\mathrm{j}$ sets $v_{j}<v_{j}^{R}$, it makes negative profits. On the contrary, if firm $\mathrm{j}$ sets $v_{j}>v_{j}^{R}$ no customer buys from it.

iii. the pair $v_{i}^{R}$ and $v_{j}^{R}$ is the unique possible equilibrium pair of prices. For $v_{i}=v_{j}<v_{i}^{R}, \quad \Pi_{i}^{R}\left(v_{i}, v_{j}\right)<0=\Pi_{i}^{R}\left(v_{i}+\varepsilon, v_{j}\right)$, when $\varepsilon>0$ and sufficiently small. For $v_{i}=v_{j}>v_{i}^{R}$, then 
$\Pi_{i}^{R}\left(v_{i}, v_{j}\right)=1 / 2 \Pi_{i}^{R}\left(v_{i}-\varepsilon, v_{j}\right)$ (when $\varepsilon>0$ and sufficiently small), as all customers patronise the lower-price firm.

Note that the restriction imposed in the Proposition to the values of the transportation cost ensures that firms obtain nonnegative profits in equilibrium for any pair of symmetric locations.

The main reason of the result reported in the Proposition is the following. Because of the nature of the expression for profits in

[2], profits obtained when undercutting the rival and serving all the market line are always twice as much the profits obtained by matching the rival's price. This implies that each firm always finds profitable to shave any market price except the price that gives zero profit. As a result, the only possible equilibrium shows the typical feature of the standard Bertrand duopoly, with both firms simply breaking even. However, the market equilibrium does not show any efficiency properties typical of the Bertrand setting. This is because the firms simply average out the transportation cost across markets. While prices are equal on average to marginal cost of provision (marginal cost, here set to zero, plus transportation cost), in any local market the equilibrium price differs from the actual total marginal cost.

\section{Welfare comparisons}

This section discusses the normative properties of the equilibria obtained under the different tie-breaking rules under analysis. It has to be emphasised that the normative analysis of this section heavily rests on the fact that, under the efficient tie-breaking rule, I focus on the equilibrium where the firms select the profit maximising price among the set of equilibrium prices. 
The level of welfare generated by the different market arrangements is compared using the traditional measures given by the aggregate consumers' surplus, industry profits and social welfare as given by the unweighted sum of the two previous terms.

As for consumers' surplus, this is an exact measure of consumers' utility because the demand originates from consumers with quadratic quasi-linear preferences. As equilibria under both tie-breaking rules have the property that they are always singleprice equilibria, aggregate consumers' surplus is given by

$$
\begin{aligned}
C S^{r}\left(v_{0}^{r}, v_{1}^{r}\right) & =\frac{1}{2} \int_{v_{0}^{r}}^{1}(1-v) d v+\frac{1}{2} \int_{v_{1}^{r}}^{1}(1-v) d v \\
& =\int_{v_{i}^{r}}^{1}(1-\bar{v}) d \bar{v} \quad \text { where } i=0 \text { or } 1
\end{aligned}
$$

where $r=E, R$.

Total profits $\Pi^{r}$, with $r=E, R$, are simply evaluated using

$$
\text { [1] and }
$$

[2] at equilibrium prices and summing up across firms.

The results of the welfare analysis are given in the following Proposition.

Proposition 5. Assume $c<\frac{2}{1-2 x+2 x^{2}}$. Let $C S^{E}, \Pi^{E}$ and $W^{E}$ be the aggregate consumers' surplus, total firms' profit and social welfare respectively under the efficient tiebreaking rule when prices are as given in Proposition 3. Let also $C S^{R}, \Pi^{R}$ and $W^{R}$ be the aggregate consumers' surplus, total firms' profit and social welfare respectively under the random tie-breaking rule when prices are as given in Proposition 4. Then, these expressions are given in Table 3.1.

Also 


$$
\begin{array}{ll}
C S^{E}<C S^{R} & \text { when } c<\frac{4}{3-4 x} \\
C S^{R}<C S^{E} & \text { when } \frac{4}{3-4 x}<c \\
\Pi^{R}<\Pi^{E} & \forall c \\
W^{R}<W^{E} & \forall c
\end{array}
$$

Proof: Simply by comparing the welfare measures over the appropriate intervals.

First note that the maximum allowed level for $c$ is the minimum within the two maximum levels of the transportation cost for which an equilibrium exists under the two tie-breaking rules. In other words, the limitation on $c$ ensures that are taken into consideration only those values of the cost parameter for which an equilibrium exists under both tie-breaking rules.

The Proposition illustrates three main features of the equilibria obtained when different tie-breaking rules are assumed.

First, consumers are better off under the random tie-breaking rule when the value of the transportation cost is low enough. This contrasts with the usual definition of the efficient tie-breaking rule being the 'socially optimal one'. The obvious reason for this definition is that consumers' behaviour under the efficient rule is socially optimal as it minimises total transportation cost for given prices and location. However, the result reported in Proposition 5 means that, differently from what implied by the mentioned commonly used definition, consumers may be better off if they buy from a randomly selected firm instead of buying from the nearest firm. 
Table 3.1 - Equilibrium welfare measures.

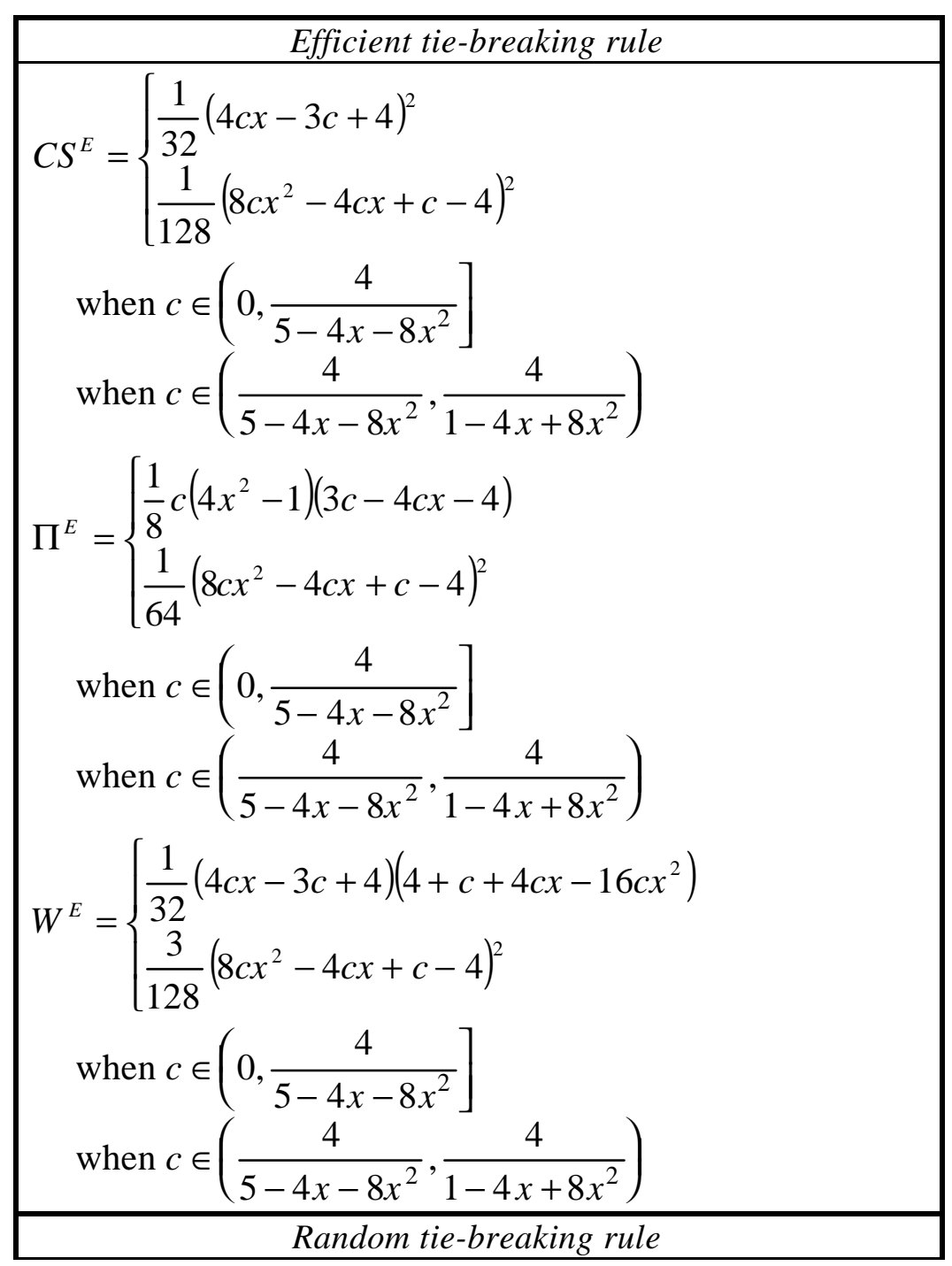




$$
\left[\begin{array}{c}
C S^{R}=\frac{1}{8}\left(2 c x^{2}-2 c x+c-2\right)^{2} \\
\text { when } c \in\left(0, \frac{2}{2 x^{2}-2 x+1}\right] \\
\Pi^{R}=0 \\
\text { when } c \in\left(0, \frac{2}{2 x^{2}-2 x+1}\right] \\
W^{R}=\frac{1}{8}\left(2 c x^{2}-2 c x+c-2\right)^{2} \\
\text { when } c \in\left(0, \frac{2}{2 x^{2}-2 x+1}\right]
\end{array}\right.
$$

In general, which one of the two equilibria obtained under the different tie-breaking rules is preferred by the consumers depends on the joint result of two different effects. A first effect is due to the different way in which competition between firms takes place when the different tie-breaking rules are assumed. Under the efficient tie-breaking rule, firms serve a given market area. Then, the price they choose is the one that (among the equilibrium prices) gives them the highest profits given the market area they supply. On the other hand, under the random tie-breaking rule, competition is much fiercer as firms are caught under the traditional Bertrand paradox; they undercut each other over the entire market line down to the price where both firms make zero profits. The other effect regards the level of total transportation cost borne by the firms and paid for by the consumers through prices. In this respect, it is clear that when consumers buy from the closest firm, firms pay an overall total transportation cost lower than when they serve also consumers at remote locations. The total result of the two effects is that, when the transportation 
cost is low enough, the competitive effect prevails and the equilibrium price is lower under the random rule. The opposite holds for high enough values of $c$.

Secondly, the comparison of firms' profits under the different tiebreaking rules is made trivial by the zero level of profits obtained by both firms when the random tie-breaking rule is assumed.

Finally, from the comparison of the levels of welfare for the society under the different tie-breaking rules, it is clear that the equilibrium when consumers buy from the nearest firm is preferred to the equilibrium under the alternative tie-breaking rule.

\section{Conclusions}

The analysis of this paper shows that an equilibrium exists in a spatial duopoly when firms adopt a uniform delivered pricing policy and products are perfectly homogeneous. With respect to the traditional no-existence conclusion, I show that it is sufficient to assume that no rationing can occur to restore the possibility of an equilibrium.

Using this assumption, I characterise the equilibria of the market under two different tie-breaking rules. As it is found that the nature of the equilibria are deeply different according the tiebreaking rule, this also highlights the relevance of the choice of the tie-breaking rule in the definition of the model.

Under the efficient tie-breaking rule, multiple equilibria are found. Indeed, any pair of identical prices within a given range is a Nash equilibrium of the game. It is also shown that these are the only possible equilibria of the game. Under the random tie-breaking rule, there exists only one possible Nash equilibrium with both firms charging the price that gives them zero profits when serving half of the customers at each location. 
As to the welfare properties of the equilibria under the different tie-breaking rules, for low enough values of the transportation costs, aggregate consumers' welfare is higher under the random tie-breaking rule despite its ex-post inefficiency. In other words, consumers are better off selecting randomly which firm they patronise than adopting the so-called socially optimal behaviour. On the other hand, the industry aggregate profits and the welfare of the society are always higher under the efficient tie-breaking rule.

\section{References}

Anderson, S. P., De Palma, A. and Thisse, J. F. (1989). Spatial price policies reconsidered. Journal of Industrial Economics, XXXVIII, 1-18.

Anderson, S. P., De Palma, A. and Thisse, J. F. (1992a). Social surplus and profitability under different spatial pricing policies. Southern Economic Journal, 58, 934-49.

Anderson, S. P., De Palma, A. and Thisse, J. F. (1992b). Discrete Choice Theory of Product Differentiation. Cambridge (MA): MIT Press.

Beckmann, M. J. and Thisse, J. F. (1986). The location of productive activities. in Nijkamp, P. (eds.), Handbook of Regional and Urban Economics, Amsterdam: Elsevier Science Publishers.

De Fraja, G. and Norman, G. (1993). Product differentiation, pricing policy and equilibrium. Journal of Regional Science, 33, 343-63. 
De Palma, A., Labbé, M. and Thisse, J. F. (1986). On the existence of price equilibria under mill and uniform delivered price policies. Université Libre de Bruxelles, Centre d'Economie Mathématique et d'Econometrie, n. $86 / 04$.

De Palma, A., Pontes, J. P. and Thisse, J. F. (1987). Spatial competition under uniform delivered pricing. Regional Science and Urban Economics, 17, 441-9.

Dixon, H. (1990). Bertrand-Edgeworth equilibria when firms avoid turning customers away. Journal of Industrial Economics, XXXIX, 131-46.

Greenhut, M. L. (1981). Spatial pricing in the U.S., West Germany and Japan. Economica, February, 79-86.

Gronberg, T. and Meyer, J. (1981). Competitive equilibria in uniform delivered pricing models. American Economic Review, 71, 758-63.

Iozzi, A. (1999). Equilibrium in spatial duopoly under uniform delivered pricing. Mimeo.

Lederer, P. J. and Hurter, A. P. J. (1986). Competition of firms: discriminatory pricing and location. Econometrica, 54, 62340.

MacLeod, W. B., Norman, G. and Thisse, J. F. (1988). Price discrimination and equilibrium in monopolistic competition. International Journal of Industrial Organization, 6, 42946.

Phlips, L. (1983). The Economics of Price Discrimination. Cambridge: Cambridge University Press.

Schuler, R. E. and Hobbs, B. F. (1982). Spatial price duopoly under uniform delivered pricing. Journal of Industrial Economics, XXXI, 175-87. 
Taha, H. A. (1988). Operations Research: An Introduction. New York: MacMillan. 